\title{
Reflexões do cuidado na saúde do homem na atenção básica
}

\author{
Catiane Maria Nogueira Berbel (iD \\ Secretaria Municipal de Saúde de Marília - Marília (SP) - Brasil \\ Faculdade de Medicina de Marília - Marília (SP) - Brasil
}

Mara Quaglio Chirelli iD

Faculdade de Medicina de Marília - Marília (SP) - Brasil

\section{RESUMO}

Objetivo: Analisar a implementação das ações na saúde do homem na visão dos gestores e equipes da Estratégia Saúde da Família e construir possíveis estratégias do cuidado ao homem a partir dos problemas identificados. Métodos: O percurso metodológico foi desenvolvido por meio da pesquisa qualitativa, no ano de 2015, em um município do interior do Estado de São Paulo. Utilizou-se na $1^{\text {a }}$ fase para a coleta de dados, a entrevista semiestruturada com gestores e coordenadores e a técnica de grupo focal com duas equipes de saúde. A análise dos dados foi realizada pelo método de análise de conteúdo, na modalidade temática, realizando-se, na $2^{\mathrm{a}}$ etapa, oficina de trabalho com as mesmas equipes no intuito de fomentar reflexões nas temáticas: o cuidado e a formação acerca da saúde do homem. Resultados: Há práticas incipientes implementadas nos serviços da Atenção Básica, considerando que a Política Nacional de Atenção Integral à Saúde do Homem é recente. O conteúdo sobre a saúde do homem não tem sido abordado nas capacitações em serviço. Durante as oficinas, surgiram propostas para estratégias de trabalho na formação e no cuidado ao homem. Conclusão: Identificou-se que os profissionais de saúde necessitam de capacitações, realização da prática de educação permanente e o apoio da gestão para a continuidade desse cuidado.

Descritores: Atenção Primária à Saúde; Estratégia Saúde da Família; Serviços de Saúde; Prática Profissional; Saúde do Homem.

\section{INTRODUÇÃO}

O Sistema Único de Saúde (SUS) é considerado o resultado da articulação de uma série de forças sociais e políticas em defesa da saúde como sendo um bem público e, ao mesmo tempo, é a forma como o estado se organizou para efetivar a garantia dos direitos humanos com a luta pelos direitos à saúde, à democracia e efetivar as políticas públicas de saúde no país ${ }^{(1)}$.

Entre as políticas públicas para viabilizar a implementação do SUS, a Portaria n. ${ }^{\circ} 648$, de 28 de março de 2006 , definiu a Atenção Básica como um conjunto de ações, nos âmbitos individual e coletivo, que abrange a promoção e a proteção da saúde, a prevenção de agravos, o diagnóstico, o tratamento, a reabilitação e a manutenção da saúde ${ }^{(2)}$.

A Estratégia Saúde da Família (ESF) é considerada uma das propostas de reorganização da atenção à saúde no Brasil, constituída como porta de entrada preferencial do sistema, devendo ordenar fluxos e contra-fluxos de pessoas em todos os cenários. Sua capacidade de resolutividade garante um amplo escopo de ações e serviços ofertados de acordo com as necessidades de saúde da população ${ }^{(3)}$. A implantação da ESF produz um impacto positivo ao valorizar ações de promoção e proteção da saúde, prevenção das doenças e atenção integral às pessoas ${ }^{(4,5)}$.

A promoção da saúde incide nas estratégias para construir saúde ofertando a atenção contínua, longitudinal e integral, nas necessidades individuais e coletivas de saúde em busca de melhorar a qualidade de vida ${ }^{(6)}$. Identifica-se ainda a necessidade de os profissionais superarem a visão tradicional de promoção da saúde, da transmissão de informações para a perspectiva de enfrentamento dos macrodeterminantes do processo saúde-doença-cuidado, buscando o empoderamento das pessoas. Outra questão a ser superada diz respeito às práticas interprofissionais

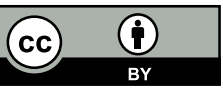


de promoção da saúde, considerando que, em muitas situações, as abordagens ainda ocorrem de forma específica e individual no cuidado realizado pelo profissional ${ }^{(7,8)}$.

Os profissionais da ESF buscam captar as necessidades individuais e coletivas de saúde, as quais estão classificadas como percebidas que relacionam as expectativas ou desejos, necessidades expressas vocalizadas nas demandas ou no uso do serviço de saúde, necessidades normativas relacionadas pela avaliação dos profissionais de saúde e as necessidades comparativas que são similares entre pessoas com as mesmas características sociodemográficas ${ }^{(9)}$.

A ausência da figura masculina nos serviços de saúde pode ser percebida por estar associada à invulnerabilidade, à força e à virilidade, características essas incompatíveis com a demonstração de sinais de fraqueza, medo, ansiedade e insegurança, representada pela procura aos serviços de saúde, o que colocaria em risco a masculinidade e aproximaria o homem das representações de feminilidade ${ }^{(10,11)}$.

Do ponto de vista das políticas públicas que norteiam o SUS, o governo brasileiro apresentou a Política Nacional de Atenção Integral à Saúde do Homem (PNAISH) em 2008, a qual está alinhada à Política Nacional de Atenção Básica com o objetivo principal de promover ações que contribuam significativamente para a compreensão da realidade singular masculina nos seus diversos contextos socioculturais e político-econômicos ${ }^{(2)}$.

Essa política deve considerar a heterogeneidade das possibilidades de ser homem. As masculinidades são construídas histórica e sócio culturalmente como um processo em permanente transformação, sendo fundamental para promover a promoção da equidade na atenção a essa população(12).

Dados epidemiológicos de morbimortalidade sinalizam o gênero masculino como mais vulnerável por padecer mais de condições severas, causas externas e crônicas de saúde, bem como, morrer mais cedo do que as mulheres. Os autores destacam a necessidade de incorporar criticamente as perspectivas de gênero relacional nas políticas públicas de saúde ${ }^{(13,14)}$.

Os homens experimentam maiores taxas de mortalidade em todas as idades. Relutam frequentemente em procurar assistência médica, considerando fraqueza masculina e vulnerabilidade, o que resulta em uma baixa acessibilidade da população masculina aos serviços preventivos da atenção primária(15).

Neste cenário de mudanças, com intuito de avaliar o serviço de saúde, mais especificamente a Atenção Básica (AB) no que se refere ao acesso e à qualidade, o Ministério da Saúde criou, em 2011, o Programa Nacional de Melhoria do Acesso e da Qualidade (PMAQ) ${ }^{(16)}$.

O PMAQ está organizado em quatro fases: Adesão e Contratualização, Desenvolvimento, Avaliação Externa e Recontratualização. A Avaliação Externa é um processo desenvolvido em parceria com Instituições de Ensino e Pesquisa. $O$ instrumento de Avaliação Externa contempla elementos relacionados à estrutura, equipamentos, condições de trabalho, dizendo respeito ao acesso e à qualidade da atenção à saúde ofertada ao cidadão e à satisfação e participação do usuário dos serviços de saúde ${ }^{(16)}$.

As unidades de Saúde da Família (USF) de um município do interior de São Paulo, Brasil, participaram da avaliação externa do PMAQ no ano de 2012 e 2013. As unidades de saúde vivenciaram o momento da avaliação da equipe quanto à subdimensão Organização do Processo de Trabalho Atenção integral à saúde do homem, na qual a equipe se autoavaliava. Um dos pontos que chamou atenção foi a avaliação da implementação da PNAISH frente a suas ações, exigindo maiores investimentos ${ }^{(12)}$. O desafio desse contexto, portanto, é transformar a PNAISH em ações de saúde, considerando a complexidade do ambiente social e cultural em que os problemas e as práticas acontecem, transcendendo o enfoque biologicista predominante no cotidiano das unidades de saúde.

Diante desse cenário Federal e Municipal, partiu-se do pressuposto de que os profissionais da saúde, durante sua formação, têm pouca apropriação e vivência relacionadas à Política de Atenção à Saúde do Homem e que, nos serviços de saúde, também há dificuldades para se organizar as atividades que contemplem tal política por essa ser recente e a formação e a capacitação nos serviços ainda não sustentarem a prática profissional necessária para sua implementação.

Diante desse contexto, objetivou-se analisar a implementação das ações na saúde do homem na visão dos gestores e equipes da Estratégia Saúde da Família e construir possíveis estratégias do cuidado ao homem a partir dos problemas identificados.

\section{MÉTODOS}

Trata-se de um estudo descritivo, exploratório, com abordagem qualitativa(17).

A pesquisa foi realizada em 2015, em um município do interior de São Paulo, Brasil, em duas Unidades de Estratégia Saúde da Família (USF) com os profissionais dessas equipes, denominada equipe 1 (E1) e equipe 2 
(E2), compostas por médico, enfermeira, cirurgião-dentista, auxiliar de saúde bucal, auxiliar de escrita, auxiliar de serviços gerais, auxiliar de enfermagem, agente comunitário de saúde e nutricionista, totalizando 11 participantes na E1 e 12 na E2. Participaram também os gestores da AB da Secretaria Municipal de Saúde (SMS), para que se pudesse explorar como foi implementada a PNAISH na perspectiva da gestão.

As USFs foram escolhidas por amostra de conveniência, utilizando-se como critério de inclusão: equipes que cooperam com a formação de Medicina e/ou Enfermagem e que obtiveram a maior e menor nota das respostas do PMAQ na "subdimensão: Organização do Processo de Trabalho Atenção integral à Saúde do Homem". A E1 foi selecionada por ter o menor resultado, apresentando nota zero, em uma escala de zero a dez, nos anos de $2012 \mathrm{e}$ 2013, e a E2 não tendo participado da avaliação em 2012, teve nota oito como resultado na área em 2013.

Os gestores de cursos técnicos e de graduação na área da saúde participaram da pesquisa para se considerar como tem ocorrido a formação inicial dos profissionais para atuar nessa política.

A coleta de dados foi realizada com dez Gestores dos Cursos de Formação (Medicina, Enfermagem, Odontologia, técnico de enfermagem, agente comunitário de saúde e auxiliar de saúde bucal), nominados de GCF 1 até GCF10 e quatro gestores da $A B$ da SMS, sendo nominado de $G A B$ e o seu número (GAB1 até GAB4), totalizando 14 participantes.

A faixa etária predominante de sete $(50 \%)$ gestores fica entre 40 e 49 anos. Conforme a titulação, encontramse quatro $(28,5 \%)$ gestores com pós-graduação Lato Sensu e 10 gestores $(71,5 \%)$ com pós-graduação Stricto Sensu. Quanto ao tempo de atuação como gestores, seis profissionais trabalham entre um e cinco anos (43\%), cinco entre 10 e 15 anos (36\%) e três de 6 a 9 anos (21\%). Entre eles, o gestor de curso de formação tem maior tempo de atuação. Já a metade dos gestores da atenção básica apresenta maior tempo e a outra metade, entre um e cinco anos.

Realizou-se coleta com os gestores no período de setembro a dezembro de 2015, por meio de entrevista semiestruturada individual ${ }^{(18)}$, utilizando-se, como disparadores da entrevista, questões sobre como ocorre o cuidado à população masculina e como é desenvolvida a formação dos profissionais de saúde relativa aos cuidados à saúde do homem. A entrevista foi gravada com anuência dos entrevistados e transcrita integralmente.

Com as duas equipes das USF realizou-se a coleta de dados por meio do grupo focal ${ }^{(19)} \mathrm{em}$ um único encontro com cada equipe, com média de duração de 45 minutos, sendo gravadas as falas e transcritas integralmente para posterior análise. As equipes foram nomeadas na apresentação dos dados por Grupo focal 1 (GF1) da E1 e E2 (GF2), utilizando-se disparadores de respostas com os seguintes questionamentos: Relate a forma que é realizado o cuidado voltado para a saúde do homem; qual o seu conhecimento sobre as ações da PNAISH; quais os desafios enfrentados para a prática do cuidado com os homens na USF; como se deu a formação inicial e ao longo da prática dos profissionais para realizar o cuidado aos homens.

Dentre os profissionais da ESF, 11 (39\%) têm entre 30 e 39 anos; dezenove (67\%) cursaram o ensino médio completo e nove (32\%) cursaram o ensino superior completo. Fizeram especialização e/ou residência em Saúde da Família, UTI, saúde coletiva, saúde do trabalho, envelhecimento e mestrado profissional. Quanto ao tempo de atuação na ESF, treze profissionais (46\%) trabalham entre 10 a 15 anos no programa. Destacam-se os ACS como os profissionais com maior tempo de atuação.

$\mathrm{Na}$ análise dos dados das entrevistas e do grupo focal, utilizou-se a técnica de Análise de Conteúdo, na modalidade temática ${ }^{(18)}$, obedecendo às seguintes etapas: na pré-análise a ordenação dos dados, elaboração e reelaboração de hipóteses; os conceitos teóricos gerais que orientaram a análise. Na segunda etapa realizou-se a exploração do material por meio da classificação dos dados nas categorias, elaboração de síntese, identificação dos núcleos de sentido e temas. Nessa modalidade temática, o conceito central é o tema, consistindo em descobrir os núcleos de sentido que compõem uma comunicação. Por fim, o tratamento dos resultados compreendeu a análise, a inferência e a interpretação dos dados coletados considerando os referenciais da integralidade no cuidado e educação(18).

Após a análise dos dados das entrevistas e do grupo focal serem processadas, retornou-se às duas equipes da USF, caracterizando-se a segunda fase da pesquisa, com os mesmos participantes da primeira fase e realizou-se oficina de trabalho (OT), apresentada síntese dos dados analisados dos GF1 para a E1 e GF2 para E2, para que os profissionais pudessem validá-los, refletir sobre eles e articulá-los com sua prática, bem como, identificar os problemas e suas soluções. A OT é um espaço que permite contribuir para o aprofundamento da reflexão, proporciona o compartilhamento dos saberes e constrói conhecimento numa relação entre o pesquisador e os sujeitos do campo da prática ${ }^{(20)}$. Os dados foram gravados para posterior análise, tendo as OTs em média 45 minutos de duração, sendo conduzida pela mesma pesquisadora da primeira fase.

Tanto no GF como na OT houve a participação de uma observadora, que elaborou um diário de campo, destacando os aspectos não verbais dos participantes, procurando visualizar seus gestos, expressões, entonações e alterações de ritmos. 
Reconheceram-se, no processo de análise, tanto das entrevistas, nos dois grupos focais e na oficina de trabalho, núcleos de sentido e temas semelhantes, a saber: Tema 1) O processo de implementação da política saúde do homem na atenção básica: as dificuldades, possibilidades de práticas e propostas de superação dos problemas; Tema 2) Dificuldades de acesso dos homens aos serviços de saúde na rede básica e seus determinantes; Tema 3) A formação dos profissionais para atuar no cuidado aos homens.

A pesquisa foi submetida ao Comitê de Ética em Pesquisa da Faculdade de Medicina de Marília, sendo aprovada pelo Parecer n. ${ }^{0} 1.079 .668$.

\section{RESULTADOS E DISCUSSÃO}

Os resultados e a discussão dos dados das duas fases serão apresentados de forma articulada por terem núcleos de sentido e temas convergentes.

\section{O processo de implementação da política saúde do homem na atenção básica: as dificuldades, possibilidades de práticas e propostas de superação dos problemas}

Tanto os profissionais das equipes da USF, como os gestores de escolas de formação dos profissionais e da $A B$ admitem não conhecer a PNAISH de forma global. Durante o grupo focal e na oficina de trabalho identificam somente a prevenção do câncer de próstata como cuidado aos homens e relatam ausência de um programa e planejamento de ações voltado para esse gênero:

"Então, se a gente for pensar em política, o nosso conhecimento é pouco." (GF2)

"Na Saúde do homem está começando estruturar um programa de câncer de próstata; o município junto com a DRS está estruturado para o diagnóstico precoce para câncer de próstata. Específico para outras ações, eu não sei [...]. Nas unidades que eu acompanho, não tem nenhuma ação específica para a Saúde do Homem." (GAB3)

Verificou-se, na primeira fase, como dificuldade para a implementação da política, o não incentivo da gestão, com a falta de capacitações para a formação e atualizações das políticas públicas. As equipes mencionam interesse para compreender as necessidades da PNAISH. Também se percebeu, na segunda fase do estudo, pela devolutiva das oficinas, que as equipes refletem quanto à ausência da gestão ao apoio de planejamento para ações e aprendizagem das políticas públicas:

"As equipes estão todas prontas e dispostas para desenvolver, mas quando você não tem apoio não adianta você ter muita força de vontade. Você vai sendo barrado, nós temos que buscar nos adaptar a eles para trazer e fazer projetos para a saúde do homem". (GF1)

O Ministério da Saúde reconhece a necessidade de maior investimento, visando a melhorias no acesso ao serviço de saúde na expansão do SUS com a implantação do PNAISH. Com o propósito de qualificar os profissionais de saúde para o correto atendimento à saúde do homem identifica a necessidade de expandir ações, como implantar assistência em saúde sexual e reprodutiva, orientar os homens e familiares sobre promoção, prevenção e tratamento das enfermidades que os atingem ${ }^{(21)}$.

Evidencia-se nas equipes que o olhar ao homem também está dirigido somente à Prevenção do Câncer de Próstata, desconhecendo os cuidados específicos para lhe ofertar:

"Eu ouço mais de política voltada o novembro azul que é a prevenção do câncer de próstata através do exame de toque." (GF2)

"Eu sei que tem a política, mas falar que eu conheço inteira, não. Sabe que tem algumas estratégias até pelo $P M A Q$ que a gente respondeu sobre saúde do homem. Na verdade, a gente faz mesmo prevenção do câncer de próstata [...]." (GF1)

Corroborando a situação apontada, pode-se constatar, pela devolutiva das oficinas, que as equipes validam suas falas referentes à implantação da PNAISH no cotidiano de suas práticas:

"Não é divulgada, não passa na televisão como o câncer de mama. Essas coisas para os homens muito pouco, acho que deveriam ser mais divulgadas." (OE2)

A procura dos homens aos serviços de saúde não deve se resumir em questões de doenças agudas, urgências 
e demandas específicas como problemas urológicos. É preciso que os profissionais de saúde construam um olhar ampliado e integral para outros problemas que prejudicam a saúde e a qualidade da vida dos homens. Necessitase de ações governamentais mais consistentes, tanto relacionadas à conscientização quanto à viabilização, nesse sentido, não basta o homem decidir cuidar de si caso a rede pública não disponibilize mecanismo para isso ${ }^{(11,22)}$.

A partir dos parâmetros do PMAQ, a atenção integral à Saúde do Homem pressupõe que a equipe mantenha atualizado o cadastro da população masculina no território, além de ações para realizar busca ativa homens de 20 a 59 anos para oferta de consultas anuais e outras atividades com intenção de prevenção e promoção à saúde; ações de sensibilização da população masculina de 40 a 59 anos para prevenção de câncer de próstata e outros agravos geniturinários; oferta de atendimentos em horários alternativos que atenda às necessidades dos homens, dentre outros ${ }^{(23)}$.

Percebe-se que a equipe local e os gestores não conhecem as ações e fluxos referentes à saúde do homem. Há indícios de que o processo de implementação dessa política não teve um planejamento abarcando a formação dos profissionais, construção conjunta do planejamento entre nível central e local a partir das particularidades dos territórios adscritos da ESF, para detectar as necessidades e singularidades dos homens. É necessário estabelecer estratégias para que os profissionais tenham acesso à PNAISH e que a integrem às suas práticas cotidianas.

A gestão deveria incentivar a capacitação constante dos trabalhadores no intuito da implementação da política de saúde e rever o processo de trabalho constantemente por meio da prática de Educação Permanente em Saúde (EPS), agindo de acordo com a Política Nacional de Humanização (PNH). A partir da gestão participativa, com envolvimento e protagonismo dos sujeitos envolvidos no processo, proporcionando corresponsabilização no planejamento, e a reflexão sobre as práticas realizadas poderiam direcionar a construção das ações em nível local.

A relação que articula a política, a gestão e as práticas profissionais tem sido uma aproximação pouco usual nas discussões acerca dos modelos assistenciais e da própria questão da integralidade em saúde, geralmente problematizada, sobretudo, enquanto política e gestão(24).

Nas práticas ancoradas na integralidade do cuidado, propõem-se que a promoção, prevenção, recuperação da saúde e reabilitação de agravos são ações que não podem ser compartimentalizadas. Se trabalhadas em todos os seus aspectos de forma dinâmica, na perspectiva de uma abordagem integral, autônoma e resolutiva pode-se modificar o processo de saúde e doença de um indivíduo, família e comunidade ${ }^{(25)}$.

Uma das possibilidades na realização da EPS se dá pela reflexão que os profissionais poderiam fazer sobre o processo de trabalho e quais valores, crenças, formas de organização do cuidado, obstáculos existentes para que o cuidado ao homem possa ser planejado e constituído no cotidiano na perspectiva da abordagem pautada na integralidade ${ }^{(24)}$.

Durante as oficinas as equipes elaboraram propostas para os cuidados específicos para a população masculina. Verbalizou-se a necessidade de conhecer a Política Nacional de Saúde do Homem para qualificar a prática do cuidado, com apropriação das ações, para que possam planejar e realizar o cuidado direcionado às necessidades dos homens, focando em abordagens específicas:

"A construção do conhecimento e talvez uma nova forma de expandir o horizonte da própria equipe. Olha, a política nacional de saúde do homem é referente a isso, o olhar é esse e talvez com isso mudar a abordagem desde a recepção deste paciente até o plano de cuidados deles, que é um pouco mais difícil de ser feito. Acho que talvez mudasse todo o conhecimento, a estruturação e a abordagem." (OE1)

Conforme se constata pelos depoimentos citados, faz-se necessário investir nos profissionais de saúde inseridos no cenário da prática: reconhecem a importância de trabalhar com abordagem específica ao cuidado ao Homem ao mencionarem que é necessário um atendimento organizado, planejado e integral para prática do cuidado. Reconhecem a necessidades de capacitações para qualificação da prática do cuidado.

\section{Dificuldades de acesso aos serviços de saúde na rede básica e seus determinantes}

Na primeira fase, captou-se também que, no processo de implementação da PNAISH, as equipes da ESF destacam ausência e distanciamento do homem com relação aos serviços da $A B$, pois consideram que a influência cultural machista não permite que o homem adoeça e procure os serviços de saúde. Há, no ambiente familiar, uma socialização de ideias que não estimula o comportamento masculino de autocuidado:

"O perfil do homem na sociedade é do homem que não adoece, é o homem que não precisa de médico, é o homem que se vira sozinho. Então, para eles, eu acredito que o meio cultural é a base, a criação. A dificuldade 
é de sair de uma sociedade enraizada no machismo mesmo que a gente não cuida dessa sociedade feminista, mas dessa sociedade que todo mundo pregou, a sociedade igualitária pro homem, isso é mais difícil, eu acho que o processo saúde doença está aí nesse miolo todo." (GF1)

Também se observa, diante do contexto, o distanciamento dos homens frente aos cuidados de promoção e prevenção à Saúde na AB: esses consideram o espaço feminilizado(26). Diante a caracterização das unidades em estudos, visualiza-se a presença de $95 \%$ do profissional do sexo feminino e $5 \%$ do sexo masculino, corroborando o dado apresentado.

Para se constituir como homem, o padrão de masculinidade é idealizado por meninos e homens não pelo desejo de serem viris, mas pelo medo de serem vistos como pouco viris ou afeminados. Ser homem está associado à invulnerabilidade, força e virilidade ${ }^{(10)}$.

Na pesquisa com os gestores deparou-se com o reconhecimento desse comportamento cultural como sendo um obstáculo para o homem cuidar de si:

"O conceito popular que a mulher tem que se prevenir e o homem não [...] por cultura, vergonha. Se é homem, se é macho, não poder, fazer o exame." (GCF2)

É percebida que a ausência dos homens nos serviços de saúde deve-se a não priorização desse usuário nas ações realizadas ${ }^{(27)}$. Esse comportamento se deve também a uma cultura machista, na qual a vergonha de procurar o serviço está presente, o que torna necessário constituir políticas de reconhecimento das necessidades e aproximação com esse público. Sendo assim, é importante que se tenha uma nova forma de pensar, tratar e atender os homens nos serviços de saúde ${ }^{(28)}$.

Identificou-se não somente as barreiras sociais e culturais construídas e perpetuadas, afastando a população masculina do âmbito da AB. Obstáculos organizacionais do SUS têm agravado essa situação. No contexto das entrevistas e nas oficinas, nas reflexões das equipes, captou-se que as unidades de saúde da $A B$ foram organizadas para o funcionamento em horários incompatíveis com o homem trabalhador, e a deficiência dos empregadores em estruturar, qualificar e incentivar seus funcionários para prevenção e promoção da saúde do homem. Isso dificulta o acesso da presença masculina nesses serviços de saúde:

"A maioria dos homens trabalha no horário comercial e então eles nunca têm tempo de procurar a assistência, não só a assistência médica, a assistência de prevenção. Vai ser difícil mudar porque eles precisam se manter, eles precisam trabalhar." (GCF5)

"Você cria um horário para ele e às vezes ele não vem porque naquele dia mudou a escala, trocou e acaba que ele prioriza novamente o trabalho [...] Quando eles vêm, eles querem o imediatismo, querem agora, tratar agora, que faz agora, tudo agora, porque ele precisa voltar e não pode perder outro dia de serviço [...]." (OE1)

$A A B$ é a porta preferencial para entrada no sistema de saúde, tornando o SUS mais eficiente, fortalecendo os vínculos entre serviço e população, contribuindo, assim, para a universalização do acesso e para a garantia da integralidade e equidade da assistência. A ocorrência de uma baixa acessibilidade da população masculina aos serviços de $A B$ constituiu-se em um importante problema de saúde pública ${ }^{(29)}$.

Com o objetivo de garantir que a população tenha acesso aos serviços de saúde fora do horário comercial, o ministério da saúde lança o programa Saúde na Hora que dispõe sobre o horário estendido de funcionamentos das Unidades de Saúde da Família, instituído pela Portaria GM n.930, de 15 de maio de 2019. A solicitação para o programa é voluntário e os municípios tem o direito de optar pela adesão ao funcionamento estendidos das unidades de saúde( ${ }^{(30)}$.

Os serviços de saúde necessitam avançar nas práticas junto a outros setores, como na indústria, comércio, dentre outros e considerar novos espaços de corresponsabilidade para promover o acesso ao serviço de saúde para a captação precoce de agravos ou promover a saúde. Torna-se adequado às equipes o diagnóstico de saúde do seu território para fortalecer laços de intersetorialidade ${ }^{(30)}$.

Em um estudo, os gestores e os profissionais entrevistados fizeram menção quanto à dificuldade do homem acessar os serviços e ter suas necessidades de cuidado atendidas. Foi também identificada fragilidade da equipe da Estratégia Saúde da Família em conciliar horários para o atendimento do homem trabalhador na unidade ${ }^{(11)}$.

\section{A formação dos profissionais para atuar no cuidado dos homens}

A formação inicial e contínua dos profissionais tem sido obstáculo para a sustentação de práticas voltadas para a saúde dos homens. Os profissionais sinalizam que no período da graduação, pós-graduação e/ou cursos e 
capacitações, não tiveram formação específica voltada para os cuidados da saúde do homem. Reconhecem que o olhar para o homem está diluído na saúde do adulto, tendo enfoque nos cuidados para doenças crônicas e urológicas:

"Eu vejo que não há uma formação específica dos profissionais em relação a cuidado à saúde do homem." (GAB1) "Eu acho que não ocorre. O homem acabou se diluindo na saúde do adulto em outras políticas. Mas especificamente em pensar na especificidade do gênero masculino ainda eu acho que é muito superficial." (GCF6)

A PNAISH identifica a assistência à saúde masculina na perspectiva de linhas de cuidado que resguardem a integralidade e orienta a APS para que ela não se restrinja somente à recuperação, garantindo, sobretudo, a promoção da saúde e a prevenção de agravos evitáveis. Apesar da criação dessa política específica, os profissionais precisam incorporar um olhar qualificado, contribuindo para a redução de complicações e aparecimento de agravos na população masculina ${ }^{(31)}$.

Até no momento, ainda que algumas experiências concretas para o cuidado dos homens tenham sido desenvolvidas, esbarra-se em diversos obstáculos, como a falta de preparo dos profissionais de saúde para atender à clientela masculina, a inexistência de material educativo específico, ausência de uma política referenciada, como as propostas do movimento feminista. Percebe-se poucos recursos governamentais para formular e executar essa política ${ }^{(27)}$.

Não é demais insistir que esse investimento no aprendizado do profissional, que já está no trabalho é imprescindível para que se construam novos modos de aprender e de trabalhar em saúde, tornando-o um profissional crítico, reflexivo, dinâmico e resolutivo diante do processo de cuidado ${ }^{(24)}$. Ademais, necessita-se superar o modelo biomédico de cuidado, considerando que as ações estão quase sempre voltadas para as doenças instaladas e com atendimento médico-centrado, sendo que os homens muitas vezes desconhecem a saúde preventiva e as atribuições da enfermeira na $\mathrm{AB}^{(32)}$.

Busca-se a construção e superação desses problemas a partir de uma formação com a inclusão de práticas de promoção da saúde e prevenção de agravos, sustentadas na concepção de integralidade no cuidado, considerando a pessoa como sujeito no processo de cuidado, portadora de necessidades, mas também se corresponsabilizando pelas ações a serem construídas no contexto desse cuidado.

\section{CONSIDERAÇÕES FINAIS}

A pesquisa promoveu o conhecimento das ações realizadas aos homens pelas equipes de saúde na Atenção Básica, o olhar dos gestores para esse cuidado e como tem ocorrido a formação desses profissionais para essa temática. Captou-se que o processo de implementação da PNAISH apresenta desafios com relação ao planejamento e realização das ações locais, além de uma formação profissional inicial e contínua que sustente as propostas de ações da política. Proporcionou também um repensar sobre as práticas profissionais em saúde e a estruturação organizacional tanto da ESF e das instituições formadoras no âmbito da saúde do homem.

Foi possível compreender que os profissionais da ESF realizam os cuidados com pouca sustentação teóricoprática durante a graduação ou nos serviços de saúde, visto que os profissionais não tiveram abordagem específica sobre o cuidado a saúde do homem, na perspectiva da integralidade, durante sua formação. Além disso, os serviços de saúde também não têm promovido processo de capacitação sobre o assunto desde a implantação dessa política. As equipes propuseram a formação dos profissionais, tendo o apoio da gestão para a implementação e continuidade do cuidado com as ações específicas aos homens.

Este estudo sugere a elaboração de possíveis intervenções para a educação dos profissionais ao cuidado ao homem nas oficinas de produção de conhecimento e resolução de problemas. É preciso melhorar a organização do trabalho nas unidades de saúde para atender as necessidades dos homens, esclarecer e construir, junto com os empregadores estratégias de cuidados para essa população alvo. Propõe-se ainda avançar nas investigações sobre a temática pesquisando como os homens têm utilizado os serviços de saúde da Atenção Básica e as perspectivas de possíveis mudanças nas práticas profissionais.

\section{CONFLITOS DE INTERESSE}

As autoras declaram que não houve conflitos de interesses na pesquisa realizada.

\section{CONTRIBUIÇÕES}

Catiane Maria Nogueira Berbel contribuiu com a concepção e o projeto, a revisão crítica relevante do conteúdo 
intelectual, a coleta e análise dos dados e a aprovação final da versão a ser publicada; Mara Quaglio Chirelli contribuiu com a análise e interpretação dos dados, a revisão crítica relevante do conteúdo intelectual e a aprovação final da versão a ser publicada.

Manuscrito baseado na dissertação apresentada ao Programa de Mestrado Profissional "Ensino em Saúde" da Faculdade de Medicina de Marília. Título: Saúde do Homem: da Educação ao Cuidado. 2016. 76 páginas.

\section{REFERÊNCIAS}

1. Malta DC, Morais OL Neto, Silva MMA, Rocha D, Castro AM, Reis AAC, et al. National Health Promotion Policy (PNPS): chapters of a journey still under construction. Ciênc Saúde Colet. 2016;21(6):1683-94.

2. Barbosa YO, Menezes LPL, Santos JMJ, Cunha JO, Menezes AF, Araújo DC, et al. Access of men to primary health care services. Rev Enferm UFPE. 2018;12(11):2897-905.

3. Brasil. Ministério da Saúde. Portaria n. 2436, de 21 de setembro de 2017. Aprova a Política Nacional de Atenção Básica, estabelecendo a revisão de diretrizes para a organização da Atenção Básica, no âmbito do Sistema Único de Saúde (SUS). Diário Oficial da União: seção 1:68, Brasília, DF, 22 set 2017.

4. Pinheiro R. Integralidade em saúde. In: Fundação Oswaldo Cruz; Escola Politécnica de Saúde Joaquim Venâncio. Dicionário da Educação Profissional em Saúde. Rio de Janeiro: Fiocruz; 2009. p. 255-62.

5. Figueiredo EN. Estratégia Saúde da Família e Núcleo de Apoio à Saúde da Família: diretrizes e fundamentos: módulo político gestor [Internet]. São Paulo: UNASUS; 2010 [acesso em 2018 Jan 10]. Disponível em: http:// www.unasus.unifesp.br/biblioteca_virtual/esf/1/modulo_politico_gestor/Unidade_5.pdf

6. Malta DC, Reis AAC, Jaime PC, Morais OL Neto, Silva MMA, Akerman M. Brazil's Unified Health System and the National Health Promotion Policy: prospects, results, progress and challenges in times of crisis. Ciênc Saúde Colet. 2018;23(6):1799-809.

7. Sobral ILL, Machado LDS, Gomes SHP, Pequeno AMC, Nuto SAS, Machado MFAS. Primary health care professionals' knowledge of health promotion competencies. Rev Bras Promoç Saúde. 2018;31(2):1-7.

8. Luquis RR, Paz HL. Attitudes about and practices of health promotion and prevention among primary care providers. Health Promot Pract. 2015;16(5):745-55.

9. Osorio RG, Servo LMS, Piola SF. Necessidade de saúde insatisfeita no Brasil: uma investigação sobre a não procura de atendimento. Ciênc Saúde Colet. 2011;16(9):3741-54.

10. Gomes R, Nascimento EF, Araújo FC. Por que os homens buscam menos os serviços de saúde do que as mulheres? As explicações de homens com baixa escolaridade e homens com ensino superior. Cad Saúde Pública. 2007;23(3):565-74.

11. Berbel CMN, Chirelli MQ. Saúde do Homem: desafios da implementação do cuidado. Anais do $7^{\circ}$ Congresso Ibero-Americano em Investigação Qualitativa - CIAIQ [Internet]; 2018 Jul 10-13; Fortaleza. Fortaleza: CIAIQ; 2018 [acesso em 2020 Fev 21]. Disponível em: https://proceedings.ciaiq.org/index.php/ciaiq2018/article/ view/1796/1749

12. Ministério da Saúde (BR), Secretaria de Atenção à Saúde, Departamento de Ações Programáticas e Estratégicas. Política Nacional de Atenção Integral à Saúde do Homem: princípios e diretrizes. Brasília: Ministério da Saúde; 2009.

13. Moura EC, Santos W, Neves ACM, Schwarz E, Gomes R. Mortality in Brazil according to gender perspective, years 2000 and 2010. Rev Bras Epidemiol. 2016;19(2):326-38.

14. Luizaga CTM, Gotlieb SLD. Mortalidade masculina em três capitais brasileiras, 1979 a 2007. Rev Bras Epidemiol. 2013;16(1):87-99.

15. Rosu MB, Oliffe JL, Kelly MT. Nurse practitioners and men's primary health care. Am J Mens Health. 2017;11(5):1501-11.

16. Ministério da Saúde (BR). Saúde mais perto de você - acesso e qualidade Programa Nacional de Melhoria do Acesso e da Qualidade da Atenção Básica (PMAQ): documento síntese para avaliação externa [Internet]. 
Brasília: Ministério da Saúde; 2012 [acesso em 2018 Jan 10]. Disponível em: http://189.28.128.100/dab/docs/ sistemas/pmaq/Documento_Sintese_Avaliacao_Externa_2012_04_25.pdf

17. Minayo MCS. O desafio do conhecimento: pesquisa qualitativa em saúde. 13ª ed. São Paulo: Hucitec; 2013.

18. Minayo MCS. Pesquisa social: teoria, método e criatividade. Petrópolis: Vozes; 2016. Ciência, técnica e arte: o desafio da pesquisa social; p. 9-28.

19. Backes DS, Colomé JS, Erdmann RH, Lunardi VL. Grupo focal como técnica de coleta e análise de dados em pesquisas qualitativas. Mundo Saúde. 2011;35(4):438-42.

20. Campos RTO, Miranda L, Gama CAP, Ferrer AL, Diaz AR, Gonçalves L, et al. Oficinas de construção de indicadores e dispositivos de avaliação: uma nova técnica de consenso. Estud Pesqui Psicol. 2010;10(1):22141.

21. Mendonça VS, Andrade AN. A Política Nacional de Saúde do Homem: necessidade ou ilusão? Rev Psicol Polit. 2010;10(20):215-26.

22. Knauth DR, Couto MT, Figueiredo WS. A visão dos profissionais sobre a presença e as demandas dos homens nos serviços de saúde: perspectivas para a análise da implantação da Política Nacional de Atenção Integral à Saúde do Homem. Ciênc Saúde Colet. 2012;17(10):2617-26.

23. Ministério da Saúde (BR). Programa Nacional de Melhoria do Acesso e da Qualidade da Atenção Básica (PMAQ): manual instrutivo. Brasília: Ministério da Saúde; 2012.

24. Carvalho YM, Ceccim RB. Formação e educação em saúde: aprendizados com a saúde coletiva. In: Campos GWS, Minayo MCS, Akerman M, Drumond M Jr, Carvalho YM, organizadores. Tratado da saúde coletiva. Rio de Janeiro: Fiocruz; 2006. p. 137-70.

25. Cecilio LCO. Curso de Aperfeiçoamento em Saúde Mental: o cuidado em Saúde [Internet]. São Paulo: UNIFESP; 2015 [acesso em 2018 Jan 10]. Disponível em: https://ares.unasus.gov.br/acervo/handle/ ARES/3244

26. Couto MT, Pinheiro TF, Valença O, Machin R, Silva GSN, Gomes R, et al. O homem na atenção primária à saúde: discutindo (in)visibilidade a partir da perspectiva de gênero. Interface (Botucatu). 2010;14(33):257-70.

27. Silva NA, Silva AS, Silva ARV, Araújo TME, Rebouças CBA, Nogueira LT. Primary care assessment from a male population perspective. Rev Bras Enferm. 2018;71(2):236-43.

28. Siqueira EL, Oliveira GR, Mendes JD, Ximenes JM, Moraes KM. Atenção à saúde do homem: trabalhando a percepção do profissional enfermeiro na Estratégia Saúde da Família. SANARE. 2014;13(1):48-55.

29. Fontes WD, Barboza TM, Leite MC, Fonseca RLS, Santos LCF, Nery TCL. Atenção à saúde do homem: interlocução entre ensino e serviço. Acta Paul Enferm. 2011;24(3):430-3.

30. Brasil. Ministério da Saúde. Portaria n. 930, de 15 de maio de 2019. Institui o Programa "Saúde na Hora", que dispõe sobre o horário estendido de funcionamento das Unidades de Saúde da Família, altera a Portaria ${ }^{\circ}$ 2.436/GM/MS, de 2017, a Portaria de Consolidação n 2/GM/MS, de 2017, a Portaria de Consolidação n 6/ GM/MS, de 2017, e dá outras providências. Diário Oficial da União: seção 1:122, 17 maio 2019.

31. Silva PAS, Furtado MS, Guilhon AB, Souza N, David H. A saúde do homem na visão dos enfermeiros de uma Unidade Básica de Saúde. Esc Anna Nery. 2012;16(3):561-8.

32. Gomes R. Saúde do homem em debate. Rio de Janeiro: Fiocruz; 2011.

\author{
Endereço para correspondência: \\ Catiane Maria Nogueira Berbel \\ Secretaria Municipal de Saúde de Marília - SP \\ Av. Castro Alves, 61 \\ Bairro: Somenzari \\ CEP: 17.506-000 - Marília - SP - Brasil \\ E-mail: catianemnogueira@gmail.com
}

